\title{
A PROSPECTIVE EVALUATION OF THE COMBINED USE OF MODIFIED ALVARADO SCORE AND ULTRASONOGRAPHY IN DECREASING NEGATIVE APPENDICECTOMY RATE
}

\author{
Vivek Patel', Sunil Agrawal2, Mukesh Singh Narwaria ${ }^{3}$, Achal Gupta ${ }^{4}$ \\ ${ }_{1}^{1}$ Post Graduate Student, Department of Surgery, Gajra Raja Medical College, Gwalior, Madhya Pradesh. \\ ${ }^{2}$ Associate Professor, Department of Surgery, Gajra Raja Medical College, Gwalior, Madhya Pradesh. \\ ${ }^{3}$ Assistant Professor, Department of Surgery, Gajra Raja Medical College, Gwalior, Madhya Pradesh. \\ 4 Professor and HOD, Department of Surgery, Gajra Raja Medical College, Gwalior, Madhya Pradesh.
}

\section{ABSTRACT}

\section{BACKGROUND}

Making the diagnosis of acute appendicitis is difficult and is important for preventing perforation of the appendix and negative appendectomy results. Clinical Scoring System like Modified Alvarado Scoring System, Ultrasonography or combined use of both simultaneously are very helpful in making the early and accurate diagnosis and decreasing negative appendicectomy.

\section{OBJECTIVES}

Aim of this study is to evaluate the sensitivity, specificity and diagnostic accuracy of modified Alvarado scoring system and Ultrasonography in the diagnosis of acute appendicitis and their correlation with histopathology report and to reduce the rate of negative appendicectomy by combined use of modified Alvarado scoring system and Ultrasonography in the patients of acute appendicitis.

\section{METHODOLOGY}

A total of 97 patients who were diagnosed as having acute appendicitis and subsequently underwent emergency appendicectomy after proper explained written consent were included in this study. Data regarding demographic profile, Modified Alvarado Score, Ultrasound abdomen and histopathology report were collected and analysed statistically.

\section{RESULTS}

Sensitivity, specificity and Diagnostic Accuracy of Modified Alvarado score using cut-off score of $\geq 7$ and Ultrasound Abdomen were $92.39 \%, 40 \%, 89.69 \%$ and 88.04\%, 80\%, 87.62\% respectively. Sensitivity, Specificity, Negative Predictive Value and Diagnostic Accuracy of our combined diagnostic approach in the diagnosis of acute appendicitis were $99.99 \%, 40 \%, 100 \%$ and $96.90 \%$ respectively. Negative appendicectomy rate in the study was $5.15 \%$.

\section{CONCLUSION}

In comparison to modified Alvarado scoring system and Ultrasonography alone, combined use of Modified Alvarado Scoring System and Ultrasonography has better sensitivity, positive predictive value, negative predictive value, diagnostic accuracy with lower false positive rate making it more accurate predictor of acute appendicitis, thus helpful in early accurate diagnosis and decrease negative appendicectomy rate in the diagnosis of acute appendicitis.

\section{KEYWORDS}

Appendicitis, Ultrasonography, Modified Alvarado Scoring System (MASS).

HOW TO CITE THIS ARTICLE: Patel V, Agrawal S, Narwaria MS, et al. A prospective evaluation of the combined use of modified Alvarado score and ultrasonography in decreasing negative appendicectomy rate. J. Evolution Med. Dent. Sci. 2016;5(55):3785-3789, DOI: $10.14260 /$ jemds/2016/867

\section{INTRODUCTION}

Acute appendicitis is the most common acute surgical condition of the abdomen in all ages and common disease in surgical practice, which comprises $10 \%$ of all surgical cases in emergency department. ${ }^{1}$ Approximately, $7 \%$ of population will have appendicitis in their lifetime with a peak incidence between 10 and 30 years. ${ }^{2}$

Financial or Other, Competing Interest: None.

Submission 05-06-2016, Peer Review 28-06-2016,

Acceptance 05-07-2016, Published 11-07-2016.

Corresponding Author:

Vivek Patel,

Department of Surgery,

Gajra Raja Medical College,

Gwalior,

Madhya Pradesh.

E-mail: vivekjnmmcraipur@gmail.com

DOI: $10.14260 /$ jemds $/ 2016 / 867$
Even after elapse of more than 120 years since Fitz first described the pathophysiology of appendicitis and McBurney demonstrated how early appendectomy can prevent appendicular perforation. This common surgical disease continues to remain a diagnostic problem and can baffle best of the clinician. $(3,4)$

Removing normal appendix is an economical burden both on the patients and the health resources, while on the other hand misdiagnosis and delay in surgery can lead to complications like perforation and finally peritonitis, thus definitely increases the morbidity, mortality and cost of treatment. Many studies found that it is impractical to have a gold standard for definitive preoperative diagnosis, which leads to an appreciable rate of negative appendicectomy as reported in the world literature varying from $20-40 \%$ with its associated morbidity of around $10 \%{ }^{5}$

In order to make an early and correct diagnosis of this sometimes very elusive disease and decrease unnecessary 
appendicectomies, over the last two decades, different protocols for example Scoring system, Imaging modalities and Laboratory investigations have been introduced and tested by different researchers. Various Scoring system include Lidverg, Fenyo, Christian, Ohmann and Alvarado Scoring Systems. Alvarado in 1986 introduced a criterion for the diagnosis of acute appendicitis. The Alvarado score was modified later by Kalan in 1988, which considered only one laboratory finding and a total score of 9 instead of 10.(6,7,8,9)

Thus the aim of this study is to evaluate the sensitivity and specificity of Modified Alvarado Scoring System and Ultrasonography in the diagnosis of acute appendicitis, to evaluate diagnostic accuracy of both and their correlation with histopathology report and to reduce the rate of negative appendicectomy by combined use of Modified Alvarado Scoring System and Ultrasonography in the patients of acute appendicitis.

\section{METHODS AND MATERIALS}

This Prospective Study was conducted at Department of Surgery, Gajra Raja Medical College and J A Group of Hospitals, Gwalior, involving 97 adult patients admitted, suspected to have acute appendicitis, fulfilled the inclusion and exclusion criteria and giving written consent to be undergoing emergency appendicectomy during period of September 2014 to August 2015.

\section{Inclusion Criteria}

Were age $\geq 15$ and $\leq 70$ years and acute abdominal pain clinically presumed to be of appendicular origin.

\section{Exclusion Criteria}

Were age $<15$ years or $>70$ years, palpable mass on abdominal examination, signs of generalized peritonitis and patient who were not willing for appendicectomy.

All suspected patients had undergone clinical examination with Modified Alvarado Scoring, routine blood investigations and Ultrasound abdomen. As confirmation of diagnosis of acute appendicitis was only possible by histopathological examination of appendix. All suspected cases underwent emergency appendicectomy after well-informed written consent.

In this Study Patients were taken for Emergency Appendicectomy if

1. Modified Alvarado Score $\geq 7$ with or without ultrasound reporting suggestive of acute appendicitis.

2. Modified Alvarado Score $<7$ with ultrasound reporting suggestive of acute appendicitis.

3. Modified Alvarado Score $<7$ with negative ultrasound report with sign and symptoms suggestive of acute appendicitis, failing to subside with conservative management of 48 hours.

All patients subjected to emergency open appendicectomy were adequately prepared preoperatively with nil orally of 6 hours, parenteral fluids, electrolyte supplements and administration of broad-spectrum antibiotics intravenously.

Emergency open appendicectomy was done under spinal anaesthesia after well-informed written consent. Grid iron incision was employed in majority of cases. Intra-operative diagnosis was noted and biopsy sent for histopathological confirmation. Post-operative patients were kept nil orally, till bowel sound returned and patients were kept on parenteral fluids, electrolyte supplements, analgesics and broadspectrum antibiotics intravenously. Patients were monitored for complications and treated if required. Post-operative sutures were removed on post-operative day 7-9 and patients were discharged after histopathological confirmation. Observations regarding results of Modified Alvarado Scoring System and Ultrasonography were noted and tabulated along with intra-operative and histopathological findings. Then master chart was prepared and various factors were compared to each other using Statistical Analysis Software SPSS version 23. Detailed results and observations were prepared.

\section{OBSERVATIONS AND RESULTS}

A total of 97 patients who were diagnosed as having acute appendicitis and subsequently underwent emergency appendicectomy in the Department of Surgery, G R Medical College and J A Group of Hospitals, Gwalior, were included in this study and analysed using Statistical Analysis Software SPSS version 23 .

In our study, mean age of the sample was $29.3( \pm 1.37)$ years ranging from 15 years to 70 years with maximum number of patients $(n=34)$ belonged to $21-30$ years age groups. Our series of study also showed that male patients outnumbered female patients with M:F of 1.85:1.

Abdominal tenderness was most consistent component of Modified Alvarado Score, which was present in all the cases of study regardless of cut-off points followed by Migratory Right Iliac Fossa pain, which was present in $89.69 \%$ of cases (92.04\% in mass $\geq 7$ and $55.55 \%$ in mass $<7$ ). Other factors were consistent finding when cut-off score was $\geq 7$, while became less consistent or absent when cut-off score was $<7$ except Elevated Temperature which was equally consistent regardless of cut-off score.

In this study, Modified Alvarado Score (Using cut-off score $\geq 7$ ) diagnosed 88 patients as case of acute appendicitis. Similarly, using Ultrasound of the abdomen we were able to diagnose 82 patients. Importantly, out of the total 9 patients who were diagnosed as not having acute appendicitis by Modified Alvarado Score, 7 were later diagnosed as having acute appendicitis on Ultrasound, while 2 of them remain negative even on the ultrasound abdomen. Thus, total of 95 were diagnosed as case of acute appendicitis using our combined diagnostic approach of Modified Alvarado Score and Ultrasound of the abdomen. However, out of these 95 only 92 patients had histopathology report suggestive of acute appendicitis. Two patients had neither Modified Alvarado score $\geq 7$ nor Ultrasound abdomen positive for acute appendicitis, but both these patients had undergone procedure since both had sustained migratory right iliac fossa pain, abdominal tenderness and elevated temperature even after 2 days of conservative management. Later on histopathological examination, both patients had normal appendix.

In our study Sensitivity, Specificity, Positive Predictive Value, Negative Predictive Value and Diagnostic Accuracy of Modified Alvarado Score using cut-off score of $\geq 7$ were 92.39\%, 40\%, 96.5\%, 22\%, 89.69\% respectively. Similarly, Ultrasound Abdomen documented Sensitivity, Specificity, Positive Predictive Value, Negative Predictive Value and Diagnostic Accuracy of $88.04 \%, 80 \%, 98.7 \%, 26 \%, 87.62 \%$ 
respectively. Sensitivity, Specificity, Positive Predictive Value, Negative Predictive Value and Diagnostic Accuracy of our combined diagnostic approach in the diagnosis of acute appendicitis were $99.99 \%, 40 \%, 96.84 \%, 100 \%$ and $96.90 \%$ respectively. Negative appendicectomy rate in the study was 5/97 (5.15\%).

\section{DISCUSSION}

Acute appendicitis remains a common abdominal emergency throughout the world. Despite the advances in the diagnostic field, the diagnosis of the acute appendicitis remains an enigma for the attendant surgeon.

In this study, it was found that maximum cases presented from $21-30$ years $(35.1 \%)$ followed by $15-20$ years $(27.8 \%)$ with mean age of $29.3( \pm 1.37)$ years and M:F of 1.85:1. Similar results were also obtained in the study done by Kailash Singh et al (2008). ${ }^{10}$ Sanjot B Kurane et al (2008). ${ }^{11}$ Talukder et al (2009). ${ }^{12}$ Nautiyal et al (2009). ${ }^{13}$ Kodliwadmath HB et al (2011). ${ }^{14}$ Nasiri et al (2012). ${ }^{15}$ Swagata Brahmachari et al (2013). ${ }^{16}$ Wilasrusmee et al (2014). ${ }^{17}$ Satyajeet et al (2014). ${ }^{18}$ and Nishikant Gujar et al (2015). ${ }^{19}$

In this study, we observed that abdominal tenderness $(100 \%)$ followed by migratory right iliac fossa pain $(89.69 \%)$ was the most constant component of Modified Alvarado Score, which were present in patients of acute appendicitis. Similar results were also documented in the study of Kodliwadmath HB et al (2011). ${ }^{14}$ Shirzad Nasiri et al (2012). ${ }^{15}$ and Nishikant Gujar et al (2015). ${ }^{19}$

Overall Sensitivity, Specificity, Positive Predictive Value, Negative Predictive Value and Diagnostic Accuracy of Modified Alvarado Score using cut-off score of $\geq 7$ in the diagnosis of acute appendicitis were 92.39\%, 40\% 96.5\%, 22\% and $89.69 \%$ respectively $(\mathrm{p}<0.01)$, which was similar to study done by Baidya $\mathrm{N}$ et al (2007). ${ }^{20}$ Talukder et al (2009). ${ }^{12}$ Alamgir et al (2009).21 Thabit et al (2012).22 Nasiri et al (2012). ${ }^{15}$ Nishikant Gujar et al (2015). ${ }^{19}$ Sensitivity of Modified Alvarado Score in the study of Sanjot B Kurane et al (2008). ${ }^{11}$ Nautiyal et al (2009). ${ }^{13}$ Satyajeet et al (2014). ${ }^{18}$ was quite lower when compared to our study, while study done by Kodliwadmath HB et al (2011).14 documented sensitivity of $98.8 \%$. Davis et al (1993). ${ }^{23}$ and Sanjot B Kurane et al (2008). ${ }^{11}$ observed Positive Predictive Value of $82.9 \%$ and $75 \%$ respectively. Nautiyal et al (2009). ${ }^{13}$ documented diagnostic accuracy of $56 \%$ while Davis et al (1993). ${ }^{23}$ documented diagnostic accuracy of 71.2\%.

In our study Sensitivity, Specificity, Positive Predictive Value, Negative Predictive Value and Diagnostic Accuracy of Ultrasound abdomen in the diagnosis of acute appendicitis were $88.04 \%$ and $80 \%, 98.7 \%, 26 \%$ and $87.62 \%$ respectively ( $\mathrm{p}<0.01)$, which was comparable to study done by Puylaert et al (1987).24 Davis et al (1993).23 Charles D Douglous et al (2000). ${ }^{25}$ Shinji Himeno et al (2003). ${ }^{26}$ Sanjot B Kurane et al (2008). ${ }^{11}$ Nautiyal et al (2009). ${ }^{13}$ Kodliwadmath HB et al (2011). ${ }^{14}$ There are few studies whose findings partially or completely contradict findings of our study. Nasiri et al (2012). ${ }^{15}$ documented lower sensitivity (71.2\%) with similar specificity, Satyajeet et al (2014). ${ }^{18}$ observed lower specificity (50\%), while Nishikant Gujar et al (2015). ${ }^{19}$ found both higher sensitivity and specificity with value of $98.44 \%$ and $94.44 \%$ respectively. Satyajeet et al (2014). ${ }^{13}$ Sanjot B Kurane et al (2008). ${ }^{11}$ documented lower Positive Predictive Value of $80.48 \%$ and $82.16 \%$ respectively. Satyajeet et al (2014). ${ }^{13}$ Nasiri et al (2012). ${ }^{15}$ documented lower diagnostic accuracy of $70.9 \%$ and $72.4 \%$ respectively.
Our combined diagnostic approach in the diagnosis of acute appendicitis has Sensitivity, Specificity, Positive Predictive Value, Negative Predictive Value and Diagnostic Accuracy of 99.99\%, 40\% 96.84\%, 100\% and 96.90\% respectively $(\mathrm{p}<0.01)$, which were higher than study done by Sanjot et al (2008).11 Nautiyal et al (2010).13 Gujar et al (2015). ${ }^{19}$ However, specificity of our combined approach was $40 \%$ which was significantly lower than previous studies.

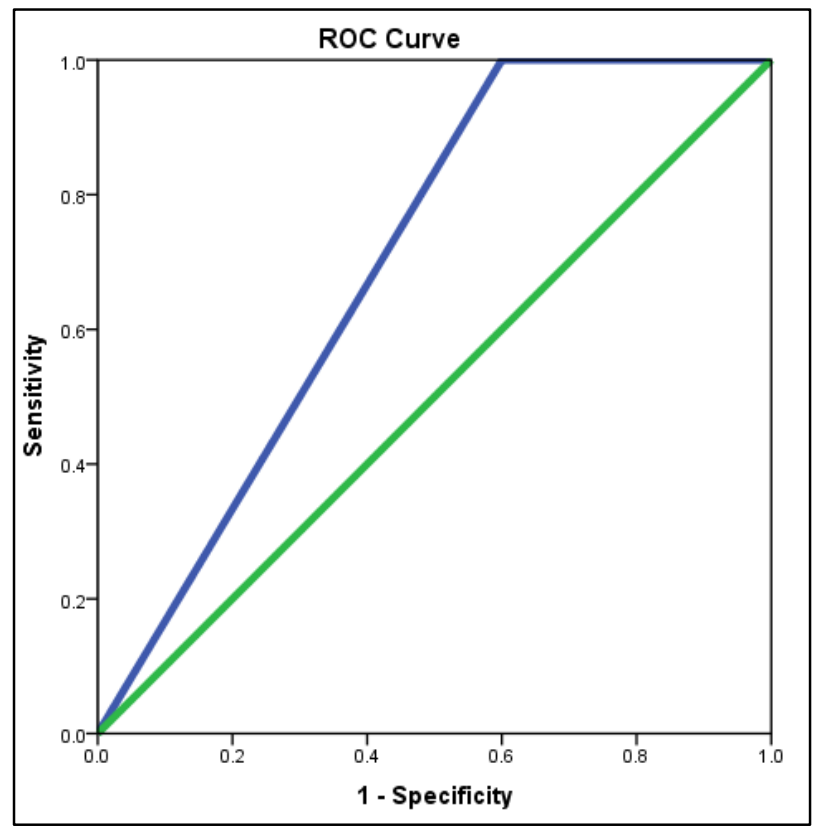

ROC curve for the diagnosis of acute appendicitis, area under curve is 0.700 with standard error of 0.150 and confidence interval of 0.406 to 0.994 .

In the study, negative appendicectomy rate was $5.15 \%$ which was similar to the study of Sanjot B Kurane et al (2008). ${ }^{11}$ and Kodliwadmath HB et al (2011).14 and significantly lower than other previous studies.

In comparison with Modified Alvarado score alone, our combined approach in the diagnosis of acute appendicitis has better sensitivity, positive predictive value, negative predictive value, diagnostic accuracy with same degree specificity and lower negative appendicectomy rate. Similarly, our combined approach has better sensitivity, positive predictive value, negative predictive value, diagnostic accuracy with lower degree of specificity and lower negative appendicectomy rate compared to Ultrasound abdomen alone. Various previous studies Sanjot et al (2008). ${ }^{11}$ Nautiyal et al (2010).13 Gujar et al (2015). ${ }^{19}$ also documented same results.

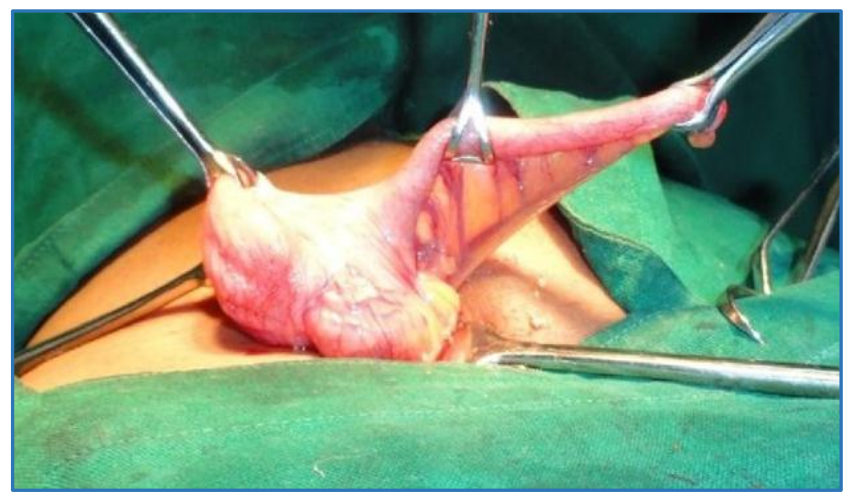

Fig. 1: Inflamed Appendix with its Mesentery 


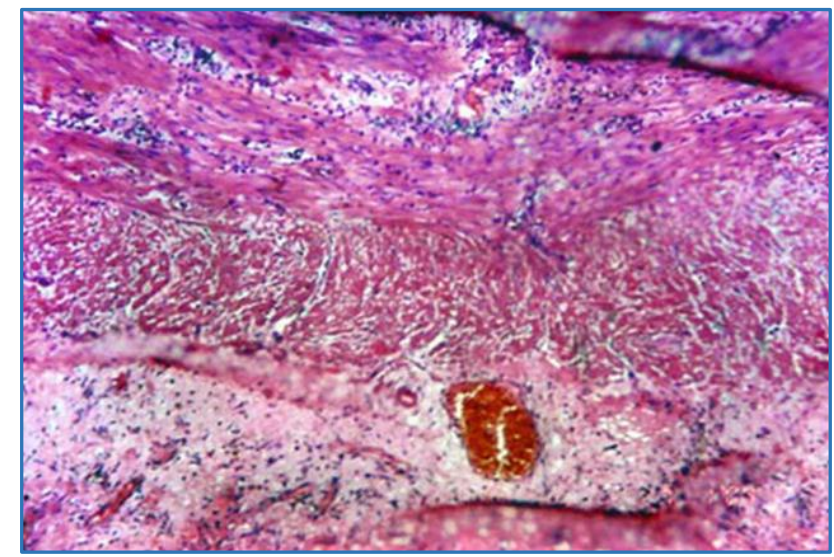

Fig. 2: Histological Section of Acute Appendicitis showing Congestion and Inflammation in Muscularis Propria Haematoxylin and Eosin Stain (HE) $(\times 100)$

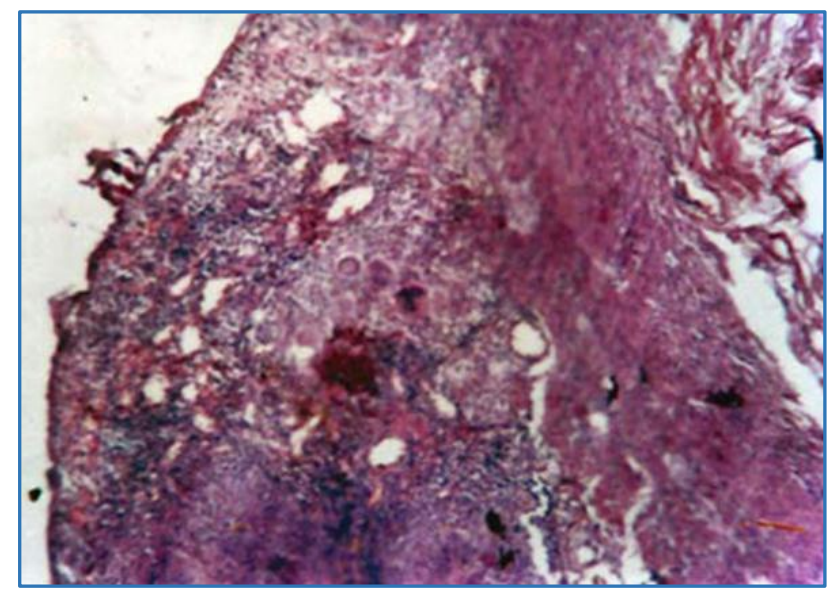

Fig. 3: Histological Section showing Langhans Giant Cells in Lamina Propria Suggestive of Tubercular Appendicitis H.E. $(\times 100)$

\begin{tabular}{|c|c|c|c|}
\hline \multirow{2}{*}{$\begin{array}{c}\text { Modified } \\
\text { Alvarado } \\
\text { Score } \\
\text { System } \\
\text { (MASS) }\end{array}$} & \multicolumn{2}{|c|}{ Histopathology Report } & \multirow[b]{2}{*}{ Total } \\
\hline & $\begin{array}{c}\text { Acute } \\
\text { Appendicitis }\end{array}$ & $\begin{array}{l}\text { Other than } \\
\text { Acute } \\
\text { Appendicitis }\end{array}$ & \\
\hline $7-9(\geq 7)$ & 85 & 03 & 88 \\
\hline$<7$ & 07 & 02 & 09 \\
\hline Total & 92 & 05 & 97 \\
\hline
\end{tabular}

\begin{tabular}{|c|c|c|c|}
\hline \multirow{2}{*}{$\begin{array}{c}\text { Ultrasound } \\
\text { Abdomen }\end{array}$} & $\begin{array}{c}|c| \\
\text { Acute } \\
\text { Appendicitis }\end{array}$ & $\begin{array}{c}\text { Other than } \\
\text { Acute } \\
\text { Appendicitis }\end{array}$ & \multirow{2}{*}{ Total } \\
\hline $\begin{array}{c}\text { Acute } \\
\text { Appendicitis }\end{array}$ & 81 & 01 & 82 \\
\hline $\begin{array}{c}\text { Normal } \\
\text { Appendix }\end{array}$ & 11 & 04 & 15 \\
\hline Total & $\mathbf{9 2}$ & $\mathbf{0 5}$ & $\mathbf{9 7}$ \\
\hline \multicolumn{2}{|c|}{ Table 2: Comparison of USG Abdomen with } \\
Histopathology \\
\hline
\end{tabular}

\begin{tabular}{|c|c|c|c|}
\hline \multirow{2}{*}{$\begin{array}{c}\text { Combined } \\
\text { Diagnostic } \\
\text { Approach }\end{array}$} & \begin{tabular}{c} 
Histopathology Report \\
Acute \\
\cline { 2 - 3 }
\end{tabular} & $\begin{array}{c}\text { Other than } \\
\text { Appendicitis } \\
\text { Appendicitis }\end{array}$ & Total \\
\hline $\begin{array}{c}\text { Acute } \\
\text { Appendicitis }\end{array}$ & 92 & 03 & 95 \\
\hline $\begin{array}{c}\text { Normal } \\
\text { Appendix }\end{array}$ & 00 & 02 & 02 \\
\hline Total & $\mathbf{9 2}$ & $\mathbf{0 5}$ & $\mathbf{9 7}$ \\
\hline
\end{tabular}

Table 3: Comparison of Our Combined Diagnostic Approach with Histopathology Report

Out of the five patients who had histopathology report other than acute appendicitis, two patients had normal appendix, two patients had tubercular appendicitis, while one patient had carcinoid on histopathology report.

\begin{tabular}{|c|c|c|}
\hline $\begin{array}{c}\text { Sl. } \\
\text { No. }\end{array}$ & $\begin{array}{c}\text { Name of the } \\
\text { Study }\end{array}$ & $\begin{array}{c}\text { Negative } \\
\text { Appendicectomy } \\
\text { Rate }\end{array}$ \\
\hline 1. & Kailash Singh et al (2008) & $16.21 \%$ \\
\hline 2. & Sanjot B Kurane et al (2008) & $3.44 \%$ \\
\hline 3. & Nautiyal et al (2009) & $8.11 \%$ \\
\hline 4. & Talukder et al (2009) & $16 \%$ \\
\hline 5. & $\begin{array}{c}\text { Kodliwadmath HB } \\
\text { et al (2011) }\end{array}$ & $6.7 \%$ \\
\hline 6. & Shirzad Nasiri et al (2012) & $10.7 \%$ \\
\hline 7. & Thabit et al (2012) & $14 \%$ \\
\hline 8. & Satyajeet Singh et al (2014) & $8.5 \%(\mathrm{MASS})$, \\
\hline 9. & Nishikant Gujar et al (2015) & $33.71 \%$ \\
\hline 10. & \multicolumn{2}{|c|}{ Our Study } \\
\hline \multicolumn{2}{|c|}{ Table 4: Comparison of Negative Appendicectomy } \\
Rate with Other Series
\end{tabular}

\begin{tabular}{|c|c|c|c|c|c|c|}
\hline \multicolumn{2}{|c|}{ Name of the Study } & SENS & SPEC & PPV & NPV & DA \\
\hline \multirow[t]{3}{*}{ Sanjot et al (2008) } & MASS & 78.26 & 83.78 & 75 & 86.11 & 81 \\
\hline & USG & 82.61 & 89.19 & 82.16 & 89.19 & 86.67 \\
\hline & Combined & 88.8 & 96.5 & 94.11 & 93.33 & 93.61 \\
\hline \multirow{3}{*}{ Nautiyal et al (2010) } & MASS & 40 & 93.33 & 93.33 & 40 & 56 \\
\hline & USG & 88.57 & 86.57 & 93.94 & 76.47 & 88 \\
\hline & Combined & 97.14 & 80 & 91.89 & 92.31 & 92 \\
\hline \multirow{3}{*}{ Gujar et al (2015) } & MASS & 98.44 & 94.4 & 99.13 & 96.49 & 96.57 \\
\hline & USG & 98.44 & 94.44 & 98.01 & 60.41 & 77.42 \\
\hline & Combined & 99.10 & 96.3 & 99.40 & 96.80 & 97.45 \\
\hline \multirow{3}{*}{ Our Study } & MASS & 92.39 & 40 & 96.5 & 22 & 89.69 \\
\hline & USG & 88.04 & 80 & 98.7 & 26 & 87.62 \\
\hline & Combined & 98.99 & 40 & 98.01 & 100 & 96.90 \\
\hline $\begin{array}{r}T c \\
s t\end{array}$ & $\begin{array}{l}\text { son of Our } \\
\text { omen in Dic }\end{array}$ & $\begin{array}{l}\text { d Appro } \\
\text { f Acute }\end{array}$ & Mo & $\begin{array}{l}\text { varado } \\
\text { ther Se }\end{array}$ & & \\
\hline
\end{tabular}




\section{SUMMARY AND CONCLUSION}

The present study concludes that Modified Alvarado Scoring System is better diagnostic tool than Ultrasonography alone in diagnosis of acute appendicitis. But still neither Modified Alvarado Scoring System nor Ultrasonography is absolute tool in reducing negative appendicectomy rate. When compared to Modified Alvarado Scoring System and Ultrasonography alone, combined use of Modified Alvarado Scoring System and Ultrasonography has better sensitivity, positive predictive value, negative predictive value, diagnostic accuracy with lower false positive rate making it more accurate predictor of acute appendicitis thus helpful in early accurate diagnosis, decrease complications thus decreasing morbidity and mortality and decrease negative appendicectomy rate in the diagnosis of acute appendicitis.

\section{REFERENCES}

1. Liu CD, McFadden DW. Acute abdomen and appendix. In: Greenfield LJ, ed. Surgery: scientific principles and practice. $2^{\text {nd }}$ edn. Philadelphia: Lippincott-Raven 1997:1246-61.

2. Liang MK, Andersson $\mathrm{AE}$, Jaffe $\mathrm{BM}$, et al. The appendix. In: Brunicardi FC, Andersen DK, Dunn DL, et al, eds. Schwartz's principles of surgery. $10^{\text {th }}$ edn. New York: Mc Graw Hill 2010:1242-57.

3. Fitz RH. Perforating inflammation of the vermiform appendix: with special reference to its early diagnosis \& treatment. Am J Med Sci 1886;92:321-46.

4. McBurney C. Experience with early operative interference in cases of diseases of the vermiform appendix. NY Med J 1889;50:676-84.

5. Mann CV. The vermiform appendix. In: Williams NS, Bulstrode CJK, O'Connell PR eds. Bailey \& Love's short practice of surgery. 26th edn. Boca Raton: CRC Press 2013:1200-12.

6. Alvarado A. A practical score for the early diagnosis of acute appendicitis. Ann Emerg Med 1986;15(5):557-64.

7. Kalan M, Talbot D, Cunliffe WJ, et al. Evaluation of the modified Alvarado score in the diagnosis of acute appendicitis: a prospective study. Ann R Coll Surg Engl 1994;76(6):418-9.

8. Ohmann C, Yang Q, Franke C. Diagnostic scores for acute appendicitis. Abdominal pain study group. Eur J Surg 1995;161(4):273-81.

9. Fenyö G, Lindberg G, Blind P, et al. Diagnostic decision support in suspected acute appendicitis: validation of a simplified scoring system. Eur J Surg 1997;163(11):8318.

10. Singh K, Gupta S, Pargal P. Application of Alvarado scoring system in diagnosis of acute appendicitis. JK Science 2008;10(2):84-6.

11. Kurane SB, Sangolli MS, Gogate AS. A one year prospective study to compare and evaluate diagnostic accuracy of modified Alvarado score and ultrasonography in acute appendicitis in adults. Indian J Surg 2008;70(3):125-9.
12. Talukder DB, Siddiq AKMZ. Modified Alvarado scoring system in the diagnosis of acute appendicitis. Journal of Armed Forces Medical College 2009;5(1):18-20.

13. Nautiyal H, Ahmad S, Keshwani NK, et al. Combined use of modified Alvarado score and USG in decreasing negative appendisectomy rate. Indian J Surg 2010;72(1):46-8.

14. Kodliwadmath HB, Bhaskaran A, Prasad CSBR, et al. Evaluation of modified Alvarado score in the diagnosis of acute appendicitis and its correlation with ultrasonography and histopathology. J Clin Bio Med Sci 2011;1(4):149-57.

15. Nasiri S, Mohebbi F, Sodagari N, et al. Diagnostic values of ultrasound and the modified Alvarado scoring system in acute appendicitis. Int J Emerg Med 2012;5:1-5.

16. Swagata B, Jajee AB. Alvarado score: a valuable clinical tool for diagnosis of acute appendicitis-a retrospective study. J Med Allied Sci 2013;3(2):63-6.

17. Wilasrusmee C, Anothaisintawee T, Poprom N, et al. Diagnostic scores for appendicitis: a systematic review of scores' performance. Br J Med Med Res 2014;4(2):711-30.

18. Singh SK, Kunal, Chitrangada. Comparative study of diagnostic accuracy of modified Alvarado score and ultrasound in acute appendicitis. IOSR Journal of Dental and Medical Sciences 2014;13(1):36-40.

19. Gujar N, Mudhol S, Chaudhari RK, et al. Determination of sensitivity and specificity of modified Alvarado score and ultrasonography in patients with acute appendicitis. Journal of Krishna Institute of Medical Sciences University 2015;4(2):89-99.

20. Baidya N, Rodrigues G, Rao A, et al. Evaluation of Alvarado score in acute appendicitis: a prospective study. Internet J of Surg 2006;9(1):1-4.

21. Alamgir, Munir A, Qadir S. Acute appendicitis: role of Alvarado scoring system in the diagnosis. Gomal Journal of Medical Sciences 2009;7(2):89-91.

22. Thabit MF, Ansari HMA, Kamoona BR. Evaluation of modified Alvarado score in the diagnosis of acute appendicitis at Baghdad teaching hospital. The Iraqi Postgraduate Medical Journal 2012;11:675-83.

23. Wade DS, Morrow SE, Balsara ZN, et al. Accuracy of ultrasound in the diagnosis of acute appendicitis compared with the surgeon's clinical impression. Arch Surg 1993;128(9):1039-46.

24. Puylaert JB, Rutgers PH, Lalisang RI, et al. A prospective study of ultrasonography in the diagnosis of appendicitis. N Engl J Med 1987;317(11):666-9.

25. Douglas CD, Macpherson NE, Davidson PM, et al. Randomised controlled trial of ultrasonography in diagnosis of acute appendicitis, incorporating the Alvarado score. BMJ 2000;321(7266):919-22.

26. Himeno S, Yasuda S, Oida Y, et al. Ultrasonography for the diagnosis of acute appendicitis. Tokai J Exp Clin Med 2003;28(1):39-44. 